\title{
REGULATION OF UNBALANCED REDOX HOMEOSTASIS INDUCED BY THE EXPRESSION OF WILD-TYPE HIV-1 VIRAL PROTEIN R (NL4-3VPR) IN FISSION YEAST
}

\author{
Zoltán Gazdag, ${ }^{1 *}$ Timea StromáJer-Rácz, ${ }^{1 *}$ Joseph Belagyi, ${ }^{2}$ \\ Richard Y. Zhao, ${ }^{3}$ Robert T. Elder, ${ }^{3}$ Eszter Virág ${ }^{1 * *}$ and Miklós Pesti ${ }^{1}$ \\ ${ }^{1}$ Department of General and Environmental Microbiology, Faculty of Sciences, University of Pécs, \\ Pécs, Hungary \\ ${ }^{2}$ Institute of Biophysics, Faculty of Medicine, University of Pécs, Pécs, Hungary \\ ${ }^{3}$ Department of Pathology, Department of Microbiology-Immunology, Institute of Human Virology, \\ University of Maryland School of Medicine, Baltimore, MD, USA
}

(Received: February 18, 2014; accepted: December 3, 2014)

\begin{abstract}
The wild-type viral protein $\mathrm{R}(\mathrm{Vpr})$ of human immunodeficiency virus type 1 exerts multiple effects on cellular activities during infection, including the induction of cell cycle $\mathrm{G}_{2}$ arrest and the death of human cells and cells of the fission yeast Schizosaccharomyces pombe. In this study, wild-type Vpr (NL4-3Vpr) integrated as a single copy gene in $S$. pombe chromosome was used to investigate the molecular impact of Vpr on cellular oxidative stress. NL4-3Vpr triggered an atypical response in early (14-h), and a wellregulated oxidative stress response in late (35-h) log-phase cultures. Specifically, NL4-3Vpr expression induced oxidative stress in the 14-h cultures leading, to decreased levels of superoxide anion $\left(\mathrm{O}_{2}{ }^{--}\right)$, hydroxyl radical $(\cdot \mathrm{OH})$ and glutathione $(\mathrm{GSH})$, and significantly decreased activities of catalase, glutathione peroxidase, glutathione reductase, glucose-6-phosphate dehydrogenase and glutathione S-transferase. In the 35-h cultures, elevated levels of $\mathrm{O}_{2}{ }^{-}$and peroxides were accompanied by increased activities of most antioxidant enzymes, suggesting that the Vpr-induced unbalanced redox state of the cells might contribute to the adverse effects in HIV-infected patients.
\end{abstract}

Keywords: HIV-1 - Vpr - oxidative stress - fission yeast - Schizosaccharomyces pombe

\section{INTRODUCTION}

The human immunodeficiency virus type-1 (HIV-1) viral protein R (Vpr) appears to be responsible for the progressive depletion of $\mathrm{CD}^{+}$lymphocytes in individuals with AIDS [18]. The wild-type Vpr (NL4-3Vpr) is localized in the mitochondria, nucleus

* The two first authors made equal contribution.

** Corresponding author; e-mail address: virag@georgikon.hu

Abbreviations: CAT, catalase; DHR 123, dihydrorhodamine 123; EPR, electron paramagnetic resonance; ET, ethidium bromide; GPx, glutathione peroxidase; GR, gluthathione reductase; GSH, glutathione; GSSG, glutathione disulfide; GST, gluthatione S-transferase; G6PD, glucose-6-phosphate dehydrogenase; HIV-1 Vpr, human immunodeficiency virus type-1 viral protein R; NL4-3Vpr, wild-type Vpr; PBN, N-tert-butyl- $\alpha$-phenylnitrone; ROS, reactive oxygen species; S. pombe, Schizosaccharomyces pombe; SOD, superoxide dismutase 
and cytoplasm [7], where it destroys the cellular regulation of the host: (i) it alters the cell morphology (elongated "cdc" phenotype cells) [24], (ii) it prevents cell proliferation by arresting cells in the G2 phase of the cell cycle [13, 24], (iii) it causes apoptosis through binding to the inner mitochondrial membrane and the release of cytochromes responsible for apoptosis [12], (iv) it activates caspase 8, the main effector of the receptor-mediated apoptotic pathway [27], (v) it causes oxidative stress in HIV-1-infected host cells $[22,28]$ and (vi) it stimulates the replication of HIV and the development of immunodeficiency $[5,14,26]$. We demonstrated earlier that the internal oxidative stress caused by wild-type $\mathrm{Vpr}$ in Schizosaccharomyces pombe (S. pombe) is partly suppressed by hydrogen peroxide $\left(\mathrm{H}_{2} \mathrm{O}_{2}\right)$-induced adaptive processes [3]. A mutation of wild-type Vpr may cause altered pathways and target molecules during HIV pathogenesis [16], indicating its structural importance. As an example, the $\mathrm{C}$-terminal end of $\mathrm{Vpr}$ is crucial for $\mathrm{G} 2$ arrest, while the N-terminal $\alpha$-helix is important for nuclear localization [7].

HIV-infected human deficiencies in the antioxidant enzyme system have been detected [8]. During HIV pathogenesis, reactive oxygen species (ROS) accumulate as biochemical by-products, causing an unbalanced redox state of the cells. The overproduction of ROS such as the superoxide anion $\left(\mathrm{O}_{2}{ }^{-}\right)$, hydroxyl radical $(\cdot \mathrm{OH})$ and peroxides $\left(\mathrm{H}_{2} \mathrm{O}_{2}\right)$ may be related to an increased activation of polymorphonuclear leukocytes [2], DNA damage or impairment of the T-cell function during HIV infection [4]. A number of studies have reported semiquantitative measurements of the total ROS in HIV-infected cells [for a review, see 22]. Both enzymatic and nonenzymatic antioxidant molecules are responsible for maintaining the cellular oxidative balance, including superoxide dismutases (SODs), glutathione peroxidase (GPx), glutathione S-transferase (GST), glutathione reductase (GR), catalase (CAT), glucose-6-phosphate dehydrogenase (G6PD), glutathione (GSH), etc.

The aim of the present study was to determine ROS separately and to quantify the changes in the antioxidant system (e.g. GSH and the most important antioxidant enzymes) during the internal oxidative stress induced by wild-type Vpr in fission yeast. To acquire more detailed information, early-log (14-h) and stationary (35-h) phase cultures were analyzed. The data obtained with wild-type Vpr permits a comparison with our earlier published data on the mutant F34IVpr protein [28].

\section{MATERIALS AND METHODS}

\section{Chemicals}

All of the chemicals used in this study were of analytical grade and were bought from Sigma-Aldrich Ltd., Budapest, Hungary. Dihydroethidium was purchased from Fluka, Buchs, Switzerland. 


\section{Cell growth and gene expression in fission yeast cells}

The NL4-3Vpr-carrying $S$. pombe strain RE007 (leu 1-32 ura4-D18 VprNL4-3::ura4+ ade6-M210 h-) and its parental strain SP223 (h-, leu1-32 ura4-294 ade6-216) were used. The processes of gene integration and induction under the control of the fission yeast $n m t 1$ promoter were described previously [20]. Cells were cultured at $30{ }^{\circ} \mathrm{C}$ in minimal growth medium (EMM) with $200 \mu \mathrm{g} \mathrm{ml}^{-1}$ and $75 \mu \mathrm{g} \mathrm{ml}^{-1}$ of the required amino acids and base [28], and were investigated in the early-log (14-h) and stationary (35-h) phases. Addition of $20 \mu \mathrm{M}$ thiamine to the growth medium caused $98 \%$ gene repression $[20,31,32]$. All experiments were carried out with the strain RE007 under gene-inducing and gene-repressing conditions in comparison with the parental strain SP223. Elimination of the effects of Vpr is not possible as the repression is not complete. The Vpr-repressed cultures are therefore not suitable as a control [20, 31, 32]. Taking this into account, we used the parental strain SP223 as a control. Other conditions and the microscopic examination of cells were as described earlier by Antal and Pesti [3].

Determination of living cell number, G2 arrest, septation index analysis, measurements of intracellular $\mathrm{H}_{2} \mathrm{O}_{2}$ and $\mathrm{O}_{2}{ }^{--}$concentrations, specific antioxidant enzyme activities and $\mathrm{Cr}(\mathrm{VI})$ reduction ability and formation of ${ }^{\circ} \mathrm{OH}$

These methods have been described in details by Stromajer-Rácz et al. [28].

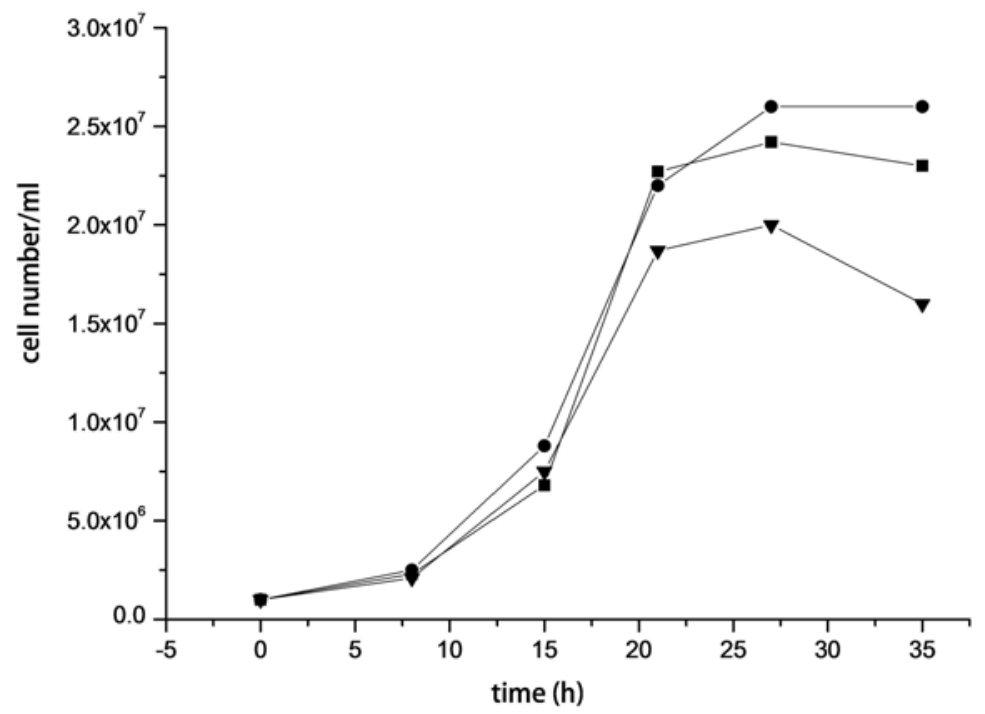

Fig. 1. Growth kinetics of S. pombe parental strain SP223 (•) and its NL4-3Vpr-carrying strain RE007 under gene-inducing $(\boldsymbol{\nabla})$ and gene-repressing $(\boldsymbol{\square})$ conditions in EMM medium at $30{ }^{\circ} \mathrm{C}$ 


\section{RESULTS}

\section{Measurement of growth inhibition, G2 arrest and septation index}

In the presence of thiamine (gene-repressing conditions), the NL4-3Vpr-carrying cells showed no significant inhibition of growth rate in comparison with the parental strain SP223 (Fig. 1). In the absence of thiamine (gene-expressing conditions), the NL4-3Vpr expression caused a 38.5\% inhibition of growth in the 35-h EMM liquid medium in comparison with the parental strain SP223 (Fig. 1).

The cell cycle G2 arrest of RE007 was determined under vpr-expressing and $v p r-$ repressing conditions in comparison with the parental SP223. Vpr induced 5\% and $90 \%$ cell cycle G2 arrest (the elongated cells exhibited the "cdc" phenotype) of the

\section{Parental strain SP223}

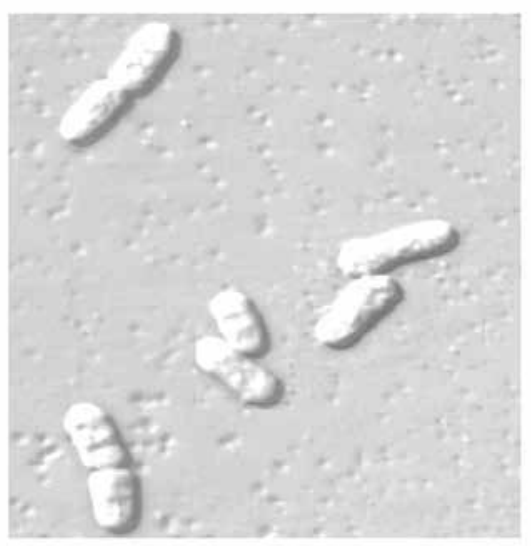

$35 \mathrm{~h}$

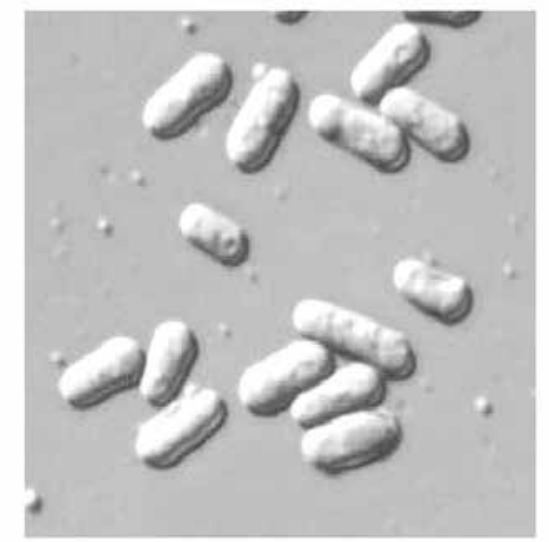

NL4-3Vpr-expressing strain RE007
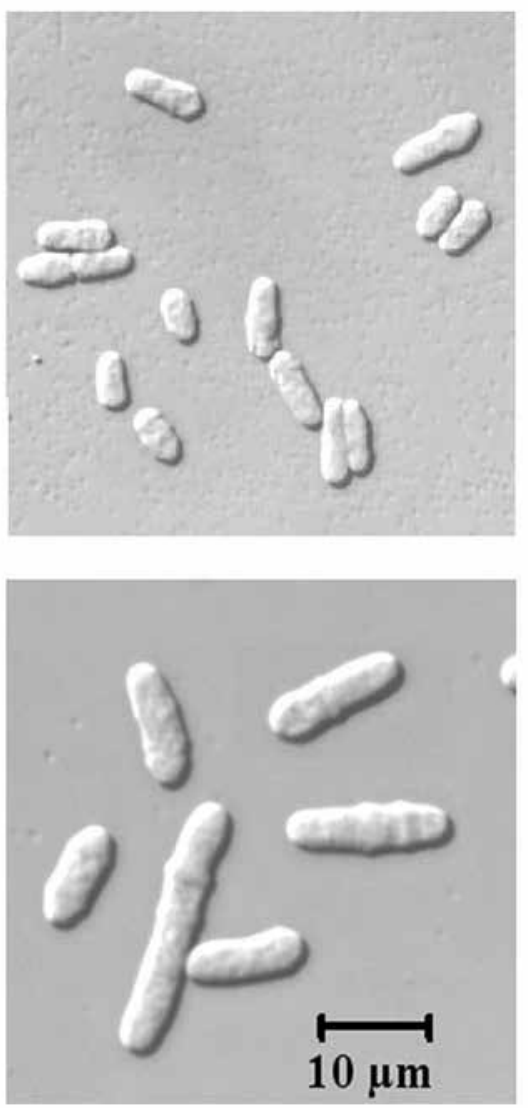

Fig. 2. Cell length as indicative of the cell cycle G2 arrest "cdc phenotype" in S. pombe parental strain SP223 and NL4-3Vpr derivative strain RE007 under gene-inducing conditions at 14 and $35 \mathrm{~h}$. Bar represents $10 \mu \mathrm{m}$ 


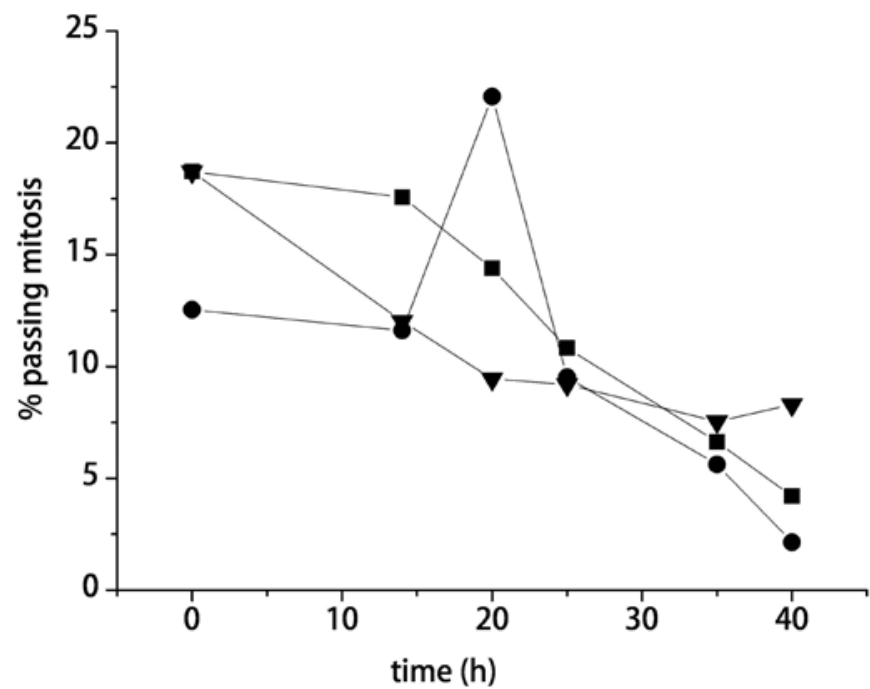

Fig. 3. Septation indices of S. pombe parental strain SP223 (•) and its NL4-3Vpr derivative strain RE007 under gene-inducing $(\boldsymbol{\nabla})$ and gene-repressing $(\boldsymbol{\bullet})$ conditions

Table 1

Summary of the effects of NL4-3Vpr on cellular enzymes involved in oxidative stress

\begin{tabular}{|c|c|c|c|c|}
\hline & \multicolumn{2}{|c|}{$14 \mathrm{~h}$} & \multicolumn{2}{|c|}{$35 \mathrm{~h}$} \\
\hline & SP223 & RE007 & SP223 & RE007 \\
\hline $\mathrm{ET}^{\mathrm{a}}$ & $1.04 \pm 0.05$ & $0.46 \pm 0.09 * * *$ & $0.012 \pm 0.001$ & $0.038 \pm 0.01 * * *$ \\
\hline $\mathrm{GSH}^{\mathrm{a}}$ & $135.13 \pm 11.83$ & $23.65 \pm 1.16^{* * *}$ & $41.04 \pm 6.99$ & $51.24 \pm 4.44$ \\
\hline $\mathrm{GSSG}^{\mathrm{a}}$ & $0.68 \pm 0.06$ & $0.10 \pm 0.05 * * *$ & $0.52 \pm 0.32$ & $4.50 \pm 0.8 * * *$ \\
\hline GSH/GSSG & 198.35 & 218.98 & 78.33 & $11.38 *$ \\
\hline $\mathrm{SOD}^{\mathrm{b}}$ & $20.97 \pm 2.28$ & $19.52 \pm 3.71$ & $4.59 \pm 0.45$ & $5.99 \pm 0.97 *$ \\
\hline $\mathrm{SOD}_{\mathrm{Mn}}^{\mathrm{b}}$ & $1.47 \pm 0.38$ & $2.93 \pm 0.8 * *$ & $0.66 \pm 0.48$ & $0.34 \pm 0.22$ \\
\hline $\mathrm{SOD}^{\mathrm{b}}{ }_{\mathrm{CuZn}}$ & $19.50 \pm 5.46$ & $16.59 \pm 5.51$ & $3.93 \pm 2.92$ & $5.64 \pm 3.71$ \\
\hline $\mathrm{CAT}^{\mathrm{c}}$ & $6.41 \pm 0.50$ & $4.70 \pm 0.34 * * *$ & $6.82 \pm 0.34$ & $8.11 \pm 2.15$ \\
\hline $\mathrm{GPx}^{\mathrm{d}}$ & $4.40 \pm 0.79$ & $0.94 \pm 0.36 * * *$ & $3.01 \pm 0.48$ & $6.43 \pm 0.7 * * *$ \\
\hline $\mathrm{GR}^{\mathrm{d}}$ & $21.75 \pm 3.09$ & $7.80 \pm 0.23 * *$ & $30.07 \pm 1.68$ & $43.66 \pm 4.81 * * *$ \\
\hline $\mathrm{G} \mathrm{PD}^{\mathrm{d}}$ & $135.26 \pm 29.11$ & $36.66 \pm 6.29 * * *$ & $206.26 \pm 22.44$ & $253.98 \pm 7.94 * *$ \\
\hline $\mathrm{GST}^{\mathrm{d}}$ & $13.27 \pm 2.03$ & $8.11 \pm 2.34 * * *$ & $18.67 \pm 1.92$ & $30.59 \pm 2.39 * * *$ \\
\hline
\end{tabular}

All cells were grown under gene-inducing conditions, i.e. without thiamine in the growth medium and enzymatic activities were measured at 14 and $35 \mathrm{~h}$ after the depletion of thiamine. Specific production values were expressed as means $\pm \mathrm{SD}$, calculated from the data of four independent experiments. ET: superoxide anion calibrated to ethidium bromide. ${ }^{*} p<5 \% ;{ }^{*} p<1 \% ;{ }^{* * *} p<0.1 \%$. Values were calculated via the Student $t$-test. ${ }^{a}$ Specific concentrations are given in nmol (mg protein) ${ }^{-1}$. ${ }^{b}$ Specific activities are given in unit (min mg protein $)^{-1}$. cSpecific activities are given in $\mu \mathrm{mol}$ (min $\mathrm{mg}$ protein $)^{-1}$. ${ }^{\mathrm{d}}$ Specific activities are given in nmol (min $\mathrm{mg}$ protein) $)^{-1}$. 
NL4-3Vpr-repressing and NL4-3Vpr-expressing cells, respectively, in the 35-h cultures (Fig. 2), but not in the 14-h cultures (Fig. 2).

The septation index data showed that the parental strain SP223 displayed normal mitotic division, whereas the NL4-3Vpr-expressing RE007 cells (but not at the high level of the NL4-3Vpr-repressing cells) exhibited a G2 arrest with halted septation between 21 and $27 \mathrm{~h}$ of cell division (Fig. 3). Moreover, significantly decreased cell numbers, with a $77 \%$ and a normal $92 \%$ living cell rate were detected in the $35-\mathrm{h}$ cultures of the $v p r$-expressing and control strains, respectively (data not presented). In this cell population, the majority of the $v p r$-expressing cells (90\%) exhibited the "cdc" phenotype (Fig. 3).
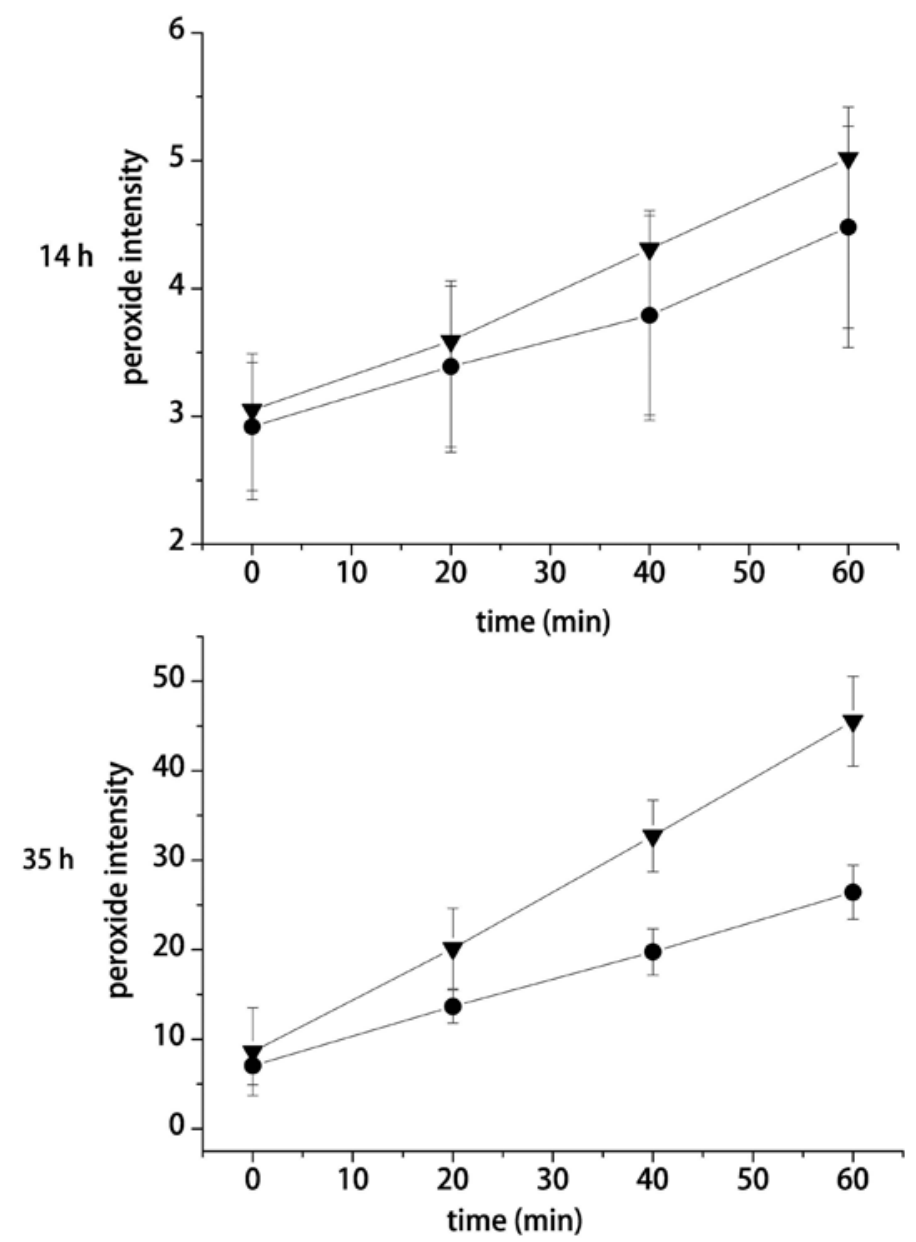

Fig. 4. Time courses of dihydrorhodamine (DHR 123) oxidation of S. pombe NL4-3Vpr-expressing RE007 ( $\boldsymbol{\nabla})$ and its parental strain SP223 $(\bullet)$ in 14-h and 35-h cultures. The conversion of DHR 123 by $5 \times 10^{6}$ cells ml-1 at $21{ }^{\circ} \mathrm{C}$ was monitored in a Perkin-Elmer fluorimeter $\left(\lambda_{\mathrm{ex}}=488 \mathrm{~nm}\right.$ and $\left.\lambda_{\mathrm{em}}=525 \mathrm{~nm}\right)$. Data are from four independent measurements; the error was $<7.5 \%$ 


\section{Measurements of intracellular $\mathrm{H}_{2} \mathrm{O}_{2}$ and $\mathrm{O}_{2}{ }^{--}$concentrations and specific antioxidant enzyme activities}

Increased or significantly increased intracellular $\mathrm{H}_{2} \mathrm{O}_{2}$ concentrations, as detected via the oxidation of dihydrorhodamine 123 (DHR 123) to rhodamine, were measured at $14 \mathrm{~h}$ and $35 \mathrm{~h}$, respectively, in the NL4-3Vpr-expressing cells of strain RE007 (Fig. 4). The specific concentration of $\mathrm{O}_{2}{ }^{-}-$calibrated to ethidium bromide (ET) for NL4-3Vpr-expressing cells was decreased in the 14-h cultures, but significantly increased in the 35-h cultures (Table 1). In comparison with the parental strain SP223, the GSH and GSSG concentrations were lower in the 14-h and higher in the 35-h cultures under NL4-3Vpr-expressing conditions (Table 1). These alterations were accompanied by a decreased and an elevated activity of GST in the 14-h and 35-h cultures, respectively (Table 1). NL4-3Vpr-expressing cells increased the activity of $\mathrm{SOD}_{\mathrm{Mn}}$ in the 14-h cultures and those of the total SODs in the 35-h cultures (Table 1), and decreased activities of all the antioxidant enzymes (except the SODs) in the early-log-phase (14-h) samples and an up-regulating effect (except for CAT) in the late log-phase (35-h) samples (Table 1) in comparison with the parental SP223 cells. The 14-h cultures of NL4-3Vpr-expressing cells demonstrated decreased specific activities of CAT, GR, G6PD and GST. No changes were measured in the specific activities of SODs (Table 1).

\section{$\mathrm{Cr}(\mathrm{VI})$ reduction ability and formation of $\cdot \mathrm{OH}$}

Samples of disrupted cells were treated for 10 min with $\mathrm{K}_{2} \mathrm{Cr}_{2} \mathrm{O}_{7}$. An EPR spectroscopy signal arising from $\mathrm{Cr}(\mathrm{V})$ (Fig. 5) at $\mathrm{g}=1.9554$ indicated the rapid reduction of $\mathrm{Cr}(\mathrm{VI})$ to $\mathrm{Cr}(\mathrm{V})$. Significantly increased $\mathrm{Cr}(\mathrm{V})$ concentrations were detected under NL4-3Vpr-expressing conditions in both the 14-h and the 35-h cultures in compari-

Table 2

$\mathrm{Cr}(\mathrm{V})$ and PBN-OH spin adduct production of disrupted parental strain SP223 and its NL4-3Vpr-carrying strain RE007

\begin{tabular}{|c|c|c|c|c|c|}
\hline \multirow{2}{*}{ Strain } & \multirow{2}{*}{ Treatment } & \multicolumn{2}{|c|}{$14 \mathrm{~h}$} & \multicolumn{2}{c|}{$35 \mathrm{~h}$} \\
\cline { 3 - 6 } & & $\mathrm{Cr}(\mathrm{V})$ & $\mathrm{PBN}-\mathrm{OH}$ & $\mathrm{Cr}(\mathrm{V})$ & $\mathrm{PBN}-\mathrm{OH}$ \\
\hline SP223 & $\mathrm{PBN}+\mathrm{Cr}(\mathrm{VI})$ & 3.07 & 2.42 & 2.45 & 0.0045 \\
\hline RE007 & $\mathrm{PBN}+\mathrm{Cr}(\mathrm{VI})$ & 3.68 & 0.48 & 3.34 & 0.0008 \\
\hline SP223 & $\mathrm{PBN}+\mathrm{Cr}(\mathrm{VI})+\mathrm{NADPH}$ & 56.09 & 0.64 & 6.45 & 0.0801 \\
\hline RE007 & $\mathrm{PBN}+\mathrm{Cr}(\mathrm{VI})+\mathrm{NADPH}$ & 18.80 & 0.16 & 5.88 & 0.1540 \\
\hline
\end{tabular}

All cells were grown under the gene-inducing conditions, i.e. without thiamine in the growth medium and samples were taken 14 and $35 \mathrm{~h}$ after the depletion of thiamine. $\mathrm{Cr}(\mathrm{V})$ and $\mathrm{PBN}-\mathrm{OH}$ spin adduct production was measured by EPR. Concentrations of $\mathrm{Cr}(\mathrm{V})$ and $\mathrm{PBN}-\mathrm{OH}$ are given in $\mu \mathrm{M}$. The SD of the mean values was $<10 \%$. A representative EPR spectrum is to be seen in Fig. 5 . 


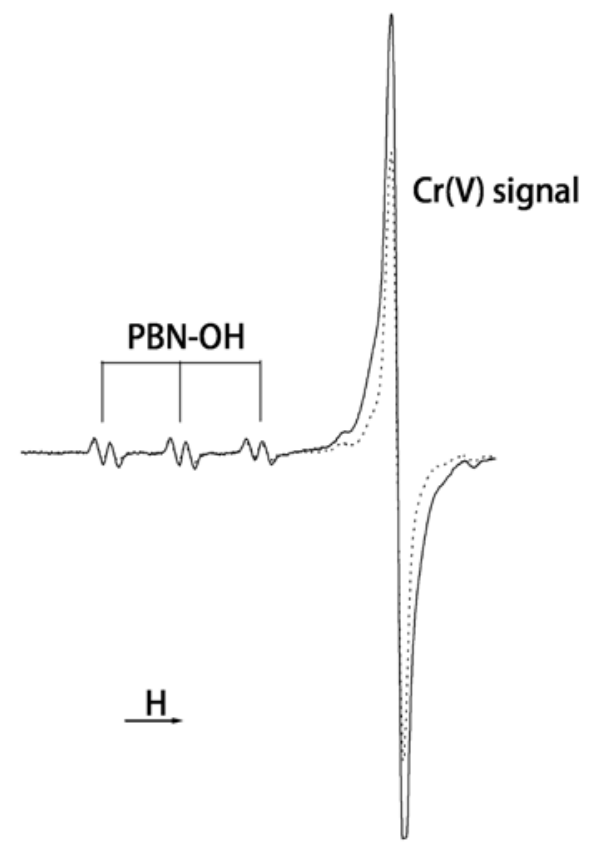

Fig. 5. Representative EPR spectra of disrupted cells of S. pombe parental strain SP223 (-) and its NL4$3 \mathrm{Vpr}$-carrying strain RE007 (- ) under gene-inducing conditions at $14 \mathrm{~h}$, recorded $10 \mathrm{~min}$ after mixing in 0.1 M PBN-containing buffer solution (pH 7.2), $2 \mathrm{mM} \mathrm{K}_{2} \mathrm{Cr}_{2} \mathrm{O}_{7}$ and $2 \mathrm{mM} \mathrm{NADPH}$. The field scan was $10 \mathrm{mT}$. Numerical data are to be seen in Table 2

son with the parental strain SP223 (Table 2). However, the addition of both $2 \mathrm{mM}$ $\mathrm{K}_{2} \mathrm{Cr}_{2} \mathrm{O}_{7}$ and $2 \mathrm{mM}$ NADPH resulted in an approximately 3-fold decrease in the $\mathrm{Cr}(\mathrm{VI})$ concentration in the 14-h cultures (Table 2), suggesting that an unbalanced redox state of the cells had developed by this time point. The addition of $\mathrm{Cr}(\mathrm{VI})$ and NADPH resulted in decreased and increased $\cdot \mathrm{OH}$ production, respectively, in the cells of RE007.

\section{DISCUSSION}

\section{NL4-3Vpr expression-induced growth inhibition, cell cycle G2 arrest and change in septation index}

The expression of NL4-3Vpr caused an inhibition (38.5\%) of growth in the 35-h cultures in comparison with the parental strain SP223, demonstrating the inhibitory effect of cell multiplication of this protein. These data are in agreement with earlier observations [3, 32]. For comparison, the multiplication of the mutant F341Vprexpressing cells stopped at $20 \mathrm{~h}$ and started again at $26 \mathrm{~h} \mathrm{[28].}$ 
It has been demonstrated previously that the expression of wild-type NL4-3Vpr in $S$. pombe induces elongated cells that are delayed or arrested at the G2/M cell cycle transition $[3,29,30]$. The $\mathrm{G} 2$ arrest mediated by Vpr utilizes the cellular signaling pathway whose physiological function is to recognize replication stress and which is strongly associated with the oxido-reduction balance of cells [33]. In our work, the Vpr-induced G2 arrest was confirmed microscopically and by determination of the septation index based on the cell fraction in a population with septum, indicating mitotic cell division (Figs 2 and 3). A rapid decrease in septum formation is detected when a G2 arrest occurs in comparison with actively growing controls, around 10 to $20 \%$ of the cells containing septa [21]. From this aspect, our data are in line with the earlier immunoblot findings that the $v p r$ expression starts at $15-17 \mathrm{~h}$, leading to morphological changes in the 17-h cultures [19]. The G2/M cell cycle block may be detected in the 35 -h cultures, leading to apoptosis preceded by morphological changes $[1,30]$. Chang et al. [6] found that wild-type vpr-expressing $S$. pombe cells began to exhibit elongation at $19 \mathrm{~h}$ and were lengthened progressively at $24 \mathrm{~h}$. Morphological changes were observed at $20 \mathrm{~h}$ in mutant F34Ivpr-expressing S. pombe cultures, in which $20 \%$ of the cells were in the mitotic phase, with more than half displaying elongated morphology [28].

Previously presented data suggested that the vpr-repressing cultures included a small percentage of cells in which expression of the Vpr protein was observed [28]. In our work, two ages of cultures were used, so as to allow a more accurate analysis of the NL4-3Vpr function. In the early-log-phase (14-h) of the cultures, visible morphological changes could not be detected, but the morphological changes were already manifested in the stationary-phase cells $(35 \mathrm{~h})$ because of the completion of G2/M blocking.

\section{NL4-3Vpr-induced depletion of GSH and increased intracellular ROS production}

It was proved that the GSH and GSSG concentrations increased with the age of the cultures, due to the increasing NL4-3Vpr expression. The elevated activity of GST in the older cultures may be a consequence of its function (GST exports GSSG from the cells if the ratio GSH/GSSG is unbalanced) [15].

An increase in ROS production was observed in the NL4-3Vpr-expressing strain RE007 as compared with its parental strain SP223. The specific concentration of $\mathrm{O}_{2}{ }^{-}$ for the NL4-3Vpr-expressing cells was decreased in the 14-h cultures, but significantly increased in the 35-h cultures. Surprisingly, the wild-type Vpr-induced $\mathrm{H}_{2} \mathrm{O}_{2}$ concentration was only about half of that induced by the mutant F341Vpr [28]. Our results are in good agreement with the earlier findings that the wild-type Vpr stimulated elevated $\mathrm{O}_{2}{ }^{-}$and total ROS production in $S$. pombe cells, as observed semiquantitatively by a fluorescence method [25]. 
The 35-h cultures exhibited elevated antioxidant enzyme activities (except for the SODs and GPx), in agreement with the findings of Lee et al. [17], explaining the increased oxidative stress tolerance of the older cells. These alterations in the NL4$3 \mathrm{Vpr}$-expressing cells might results from the decreased concentration of GSH, the changed concentration of $\mathrm{H}_{2} \mathrm{O}_{2}$ and the disturbed regulation of the oxidative stress process via the MAPK-regulated transcription factors papl and atfl. Since, the specific activities of all the examined antioxidant enzymes in the NL4-3Vpr-expressing cells were up-regulated and the concentration of GSH, as the first indicator of oxidative stress [11], was elevated in comparison with that in the parental strain SP223 in the 35-h cultures, the results allow the presumption that, under the wild-type NL4$3 \mathrm{Vpr}$-induced conditions, the cells were able to adapt to the oxidation stress conditions due to the elevated levels of $\mathrm{O}_{2}{ }^{-}$and $\mathrm{H}_{2} \mathrm{O}_{2}$ through the up-regulation of the activities of all the antioxidant enzymes.

\section{NL4-3Vpr induced a decreased ${ }^{\circ} \mathrm{OH}$ concentration in spite of the higher intracellular $\mathrm{O}_{2}{ }^{--}$and $\mathrm{H}_{2} \mathrm{O}_{2}$ levels}

The redox state of cells can be characterized by the simultaneous measurement of the reduction of $\mathrm{Cr}(\mathrm{VI})$ to $\mathrm{Cr}(\mathrm{V})$ and the ${ }^{\circ} \mathrm{OH}$ concentration by EPR spectroscopy. $\mathrm{Cr}(\mathrm{VI})$ is reduced by antioxidants (GSH, etc.) and the GR/NADPH system, and hence the quantity of $\mathrm{Cr}(\mathrm{V})$ indicates the total reduction capacity of the cell $[11,23]$. The $\cdot \mathrm{OH}$ concentration measured as a N-tert-butyl- $\alpha$-phenylnitrone-OH $(\mathrm{PBN}-\mathrm{OH})$ adduct provides information about the Fenton $\left(\mathrm{Cr}(\mathrm{V})+\mathrm{H}_{2} \mathrm{O}_{2} \rightarrow \mathrm{Cr}(\mathrm{VI})+\cdot \mathrm{OH}+\mathrm{OH}^{-}\right)$and Haber-Weiss $\left(\mathrm{O}_{2}{ }^{-}+\mathrm{H}_{2} \mathrm{O}_{2} \rightarrow{ }^{\bullet} \mathrm{OH}+\mathrm{OH}\right)$ reactions [11]. These data support the idea that Vpr-expressing cells are in an oxidized redox state [23]. In agreement with the results obtained with mutant F341Vpr-expressing cells [28], significantly decreased - $\mathrm{OH}$ production was detected in the NL4-3Vpr-expressing cells after the addition of $\mathrm{Cr}(\mathrm{VI})$ in both the 14-h and the 35-h cultures, in spite of the high concentrations of $\mathrm{O}_{2}{ }^{-}$(in the 35-h cultures) and $\mathrm{H}_{2} \mathrm{O}_{2}$ (in both cultures). These phenomena might be consequences of a disrupted metal homeostasis (decreased concentrations of redoxactive metals, e.g. $\mathrm{Fe}^{2+}$ and $\mathrm{Cu}^{2+}$ ) of strain RE007 [10]. As already suggested, this may be an atypical reaction because the addition of NADPH to the $\mathrm{Cr}(\mathrm{VI})$-tolerant strain of $S$. pombe resulted in increased $\cdot \mathrm{OH}$ production [9].

Comparison of the data relating to the 14-h and 35-h cultures of both strains permits the conclusion in the case of the Vpr-expressing strain that higher oxidative stress was observed in the older cultures due to the already occurred Vpr expression in the cells. The decreased $\cdot \mathrm{OH}$ production and SOD activities and the increased concentrations of $\mathrm{O}_{2}{ }^{-}$and $\mathrm{H}_{2} \mathrm{O}_{2}$ and the CAT activity suggest a slower Fenton reaction, which may be caused by disrupted metal homeostasis. The high level of $\mathrm{O}_{2}{ }^{-}$ definitely causes DNA oxidative damage, which may also lie in the background of the apoptotic and G2 arrest phenomena. In the case of the parental strain, this correlation 
was not observed, but a slight increase of the $\mathrm{H}_{2} \mathrm{O}_{2}$ was detected in consequence of the aging of the cultures.

To summarize, the expression of the wild-type Vpr caused an unbalanced redox state in strain RE007 in both the 14-h and the 35-h cultures in comparison with the parental strain SP223. In both cultures, the changes in the concentrations of the ROS were accompanied by changes in the GSH concentration and in the activities of specific antioxidant enzymes, which indicates a partial adaptation of the cells since the fenton reaction seems to be slowed down as a consequence of NL4-3Vpr cells adapted to the elevated concentration of $\mathrm{H}_{2} \mathrm{O}_{2}$ and $\mathrm{O}_{2}{ }^{--}$, intensifying the activity of the antioxidant enzyme system (except the SODs) in the recovery from the Vpr-induced unbalanced redox state. A typical regulation of detoxification could be observed. In the system of GSH/ROS/antioxidants, e.g. in the 35-h cultures, the increased concentration of $\mathrm{H}_{2} \mathrm{O}_{2}$ implies alterations in the activities of the detoxification enzymes CAT and GPx.

A comparison of the results with the mutant F341vpr-expressing strain [28] led to the conclusion that the mutant F341vpr gene displays a more pronounced response to oxidative stress and a higher adaptation than those for the wild-type vpr-expressing cells.

The results of this study may contribute to the knowledge relating to redox control, which can be an important therapeutic strategy for oxidative stress-associated disorders during HIV infection.

\section{REFERENCES}

1. Andersen, J. L., Rouzic, E. L., Panelles, V. (2008) HIV-1 Vpr: mechanism of G2 arrest and apoptosis. Exp. Mo. Pathol. 85, 2-10.

2. Allard, J. P., Aghdassi, E., Chau, J., Salit, I.. Walmsley, S. (1998) Oxidative stress and plasma antioxidant micronutrients in humans with HIV infection. Am. J. Clin. Nutr. 67, 143-147.

3. Antal, J., Pesti, M. (2007) The dose-dependent $\mathrm{H}_{2} \mathrm{O}_{2}$ stress response promotes increased survival of Schizosaccharomyces pombe cells expressing HIV-1 Vpr. Folia Microbiol. 51, 406-412.

4. Baruchel, S., Wainberg, M. A. (1992) The role of oxidative stress in disease progression in individuals infected by the human immunodeficiency virus. J. Leuko. Biol. 52, 111-114.

5. Buhl, R., Holroyd, K. J., Mastrangell, A. (1989) Systemic glutathione deficiency in symptom-free HIV-seropositive individuals. Lancet 2, 1294-1298.

6. Chang, F., Re, F., Sebastian, S., Sazer, S., Luban, J. (2004) HIV-1 Vpr induces defects in mitosis, cytokinesis, nuclear structure, and centrosomes. Mol. Biol. Cell 15, 1793-1801.

7. Chen, M., Elder, R. T., Yu, M., O’Gorman, M. G., Selig, L., Benarous, R., Yamamoto, A., Zhao, Y. (1999) Mutational analysis of Vpr-induced G2 arrest, nuclear localization, and cell death in fission yeast. J. Virol. 73, 3236-3245.

8. Elbim, C., Pillet, S., Prevost, M. H., Preira, A., Girard, P. M., Rogine, N., Matusani, H., Hakim, J., Israel, N., Gougerot-Pocidalo, M. A. (1999) Redox and activation status of monocytes from human immunodeficiency virus-infected patients: relationship with viral load. J. Virol. 73, 4561-4566.

9. Gazdag, Z., Pócsi, I., Belágyi, J., Emri, T., Blaskó, Á., Takács, K., Pesti, M. (2003) Chromate tolerance caused by reduced hydroxyl radical production and decreased glutathione reductase activity in Schizosaccharomyces pombe. J. Basic Microbiol. 43, 96-103.

10. Gille, G., Sigler, K. (1995) Oxidative stress and living cell. Folia Microbiol. 40, 131-152. 
11. Halliwell, B., Gutteridge, J. M. C. (2007) Free Radicals in Biology and Medicine. 4th edition. Oxford University Press, New York.

12. Jacotot, E., Ravagnan, L., Loeffler, M. (2000) The HIV-1 viral protein R induces apoptosis via a direct effect on the mitochondrial permeability transition pore. J. Exp. Med. 191, 33-46.

13. Jowett, J. B. M., Planelles, V., Poon, B., Shah, N. P., Chen, M.-L., Chen, I. S. Y. (1995) The human immunodeficiency virus type $1 \mathrm{vpr}$ gene arrests infected T cells in the G2 $1 \mathrm{M}$ phase of the cell cycle. J. Virol. 69, 6304-6313.

14. Kalebic, T., Kinter, A., Poli, G., Anderson, M. E., Meister, A., Fauci, A. S. (1991) Suppression of human immunodeficiency virus expression in chronically infected monocytic cells by gluthatione, glutathione ester, and N-acetylcysteine. Proc. Natl. Acad. Sci. (USA) 88, 986-990.

15. Kim, H. G., Park, K. N., Cho, Y. W., Park, E. H. (2001) Characterization and regulation of glutathione S-transferase gene from Schizosaccharomyces pombe. Biochim. Biophys. Acta 1520, 179-185.

16. Le Rouzic, E., Benichou, S. (2005) The Vpr protein from HIV: distinct roles along the viral life cyle. Retrovirology 11, 1-14.

17. Lee, J., Dawes, I. W., Rhoe, J. H. (1995) Adaptive response of Schizosaccharomyces pombe to hydrogen peroxide and menadione. Microbiol. 141, 3127-3131.

18. Li, G., Bukrinsky, M., Zhao, R. Y. (2009) HIV-1 viral protein R (Vpr) and its interactions with host cell. Curr. HIV Res. 7, 178-183.

19. Masuda, M., Nagai, Y., Oshima, N., Tanaka, K., Murakmi, H., Igarshi, H., Okyama, H. (2000) Genetic studies with the fission yeast Schizosaccharomyces pombe suggest involvement of Wee1, Ppa2, and Rad24 in induction of cell cycle arrest by Human Immunodeficiency Virus Type 1 Vpr. J. Virol. 74 2636-2646.

20. Maundrell, K. (1990) nmt1 on fission yeast. A highly transcribed gene completely repressed by thiamine. J. Biol. Chem. 19, 10857-10864.

21. Mitchison, J. M. (1970) Physiological and cytological methods for Schizosaccharomyces pombe Methods Cell Physiol. 4, 131-165.

22. Perl, A., Banki, K. (2004) Genetic and metabolic control of the mitochondrial transmembrane potential and reactive oxygen intermediate production in HIV disease. Redox Signal. 2, 551-573.

23. Pesti, M., Gazdag, Z., Emri, T., Farkas, N., Koósz, Z., Belágyi, J., Pócsi, I. (2002) Chromate sensitivity in fission yeast is caused by increased glutathione reductase activity and peroxide overproduction. J. Basic Microbiol. 42, 408-419.

24. Re, F., Braaten, D., Franke, E. K., Luban, J. (1995) Human immunodeficiency virus type 1 Vpr arrests the cell cycle in G2 by inhibiting the activation of p34cdc2-cyclin B. J. Virol. 69, 6859-6864.

25. Rothe, G., Kellermann, W., Valet, G. (1990) Flow cytometric parameters of neutrophil function as early indicators of sepsis- or trauma-related pulmonary or cardio-vascular organ failure. J. Lab. Clin. Med. 115, 52-61.

26. Schreck, R., Rieber, P., Baeuerle, P. A. (1991) Reactive oxygen intermediates as apparently widely used messengers in the activation of the NF-kB transcription factor and HIV-1. EMBO J. 10, 22472258.

27. Stewart, S. A., Poon, B., Song, J. Y., Chen, I. S. (2000) Human immunodeficiency virus type 1 vpr induces apoptosis through caspase activation. J. Virol. 74, 3105-3111.

28. Stromajer-Rácz, T., Gazdag, Z., Belágyi, J., Vágvölgyi, Cs., Zhao, Y., Pesti, M. (2009) Oxidative stress induced by HIV-1 F34IVpr in Schizosaccharomyces pombe is one of its multiple functions. Exp. Mol. Path. 88, 38-44.

29. Zhang, C., Rasmussen, C., Chang, L.-J. (1997) Cell cycle inhibitory effects of HIV and SIV Vpr and Vpx in the yeast Schizosaccharomyces pombe. Virology 230, 103-112.

30. Zhao, Y., Cao, J., O-Gorman, M. R., Yu, M., Yogev, R. (1996) Effect of human immunodeficiency virus type 1 Protein $\mathrm{R}$ (vpr) gene expression on basic cellular function of fission yeast Schizosaccharomyces pombe. J. Virol. 5821-5826.

31. Zhao, Y., Elder, R. T., Chen, M., Cao, J. (1998) Fission yeast expression vectors adapted for large scale cloning and GFP fusion with positive screening. BioTechniques 25, 438-444. 
32. Zhao, Y., Yu, M., Chen, M., Elder, R. T., Yamamoto, A., Cao, J. (1998) Pleiotropic effects of HIV-1 protein $\mathrm{R}$ (Vpr) on morphogenesis and cell survival in fission yeast and antagonism by pentoxifylline. Virology 246, 266-276.

33. Zimmerman, E. S., Chen, J., Andersen, L. J., Ardon, O., DeHart, J. L., Blackett, J., Choudhary, S. K., Camerini, D., Nghiem, P., Planelles, V. (2004) Human immunodeficiency virus type 1 Vpr-mediated $\mathrm{G} 2$ arrest requires raR17 and Hus1 and induces nuclear BRCA1 and g-H2AX focus formation. Mol. Cell. Biol. 24, 9286-9294. 